\title{
Knowledge, Attitude and Practice (KAP) Study on Contraceptive Prevalence among Health Care Providers
}

\author{
Article by ${ }^{1}$ Robina Kousar, ${ }^{2}$ Muhammad Afzal \\ ${ }^{1}$ Senior Lecturer, University of Lahore, Pakistan \\ ${ }^{2}$ Assistant Professor, University of Lahore, Pakistan \\ Email: muhammad.afzal@lsn.uol.edu.pk
}

\begin{abstract}
Objective: To assess the knowledge, attitude and practices of contraceptives among health care providers.

Methodology: A cross sectional study was conducted from Feb 2015 to January 2016on health care providers of public Hospitals in Lahore. A total of 216 participants were selected who has 2 or more children and lies at the age of 20 above. Data was collected on a selfdeveloped close ended questionnaire. Responses were analyzed on Statistical Package of social Sciences using descriptive statistics.

Results: Mean age 31-40 years (50 \%) had secondary school certificate, 86 (39.8\%) Nurse Midwife, 190 (88\%) were having two children 94(43.5\%). Regarding the knowledge and awareness about contraceptives 212 (98.1\%) respondents had knowledge about contraceptives and 172 (79.1\%) got the knowledge from professional study. 82 (38\%), 50 (23.1\%) said that Hospital and Family Planning Clinic respectively are the resource places for contraceptives. Overall 84.3\% health care providers were using different contraceptive methods. Condom used by partners was $74(34.3 \%)$ but the preferred method of participants was oral contraceptive pills 34 (15.7\%). Moreover, 134 (62\%) had no constrains in using contraceptives and constrains faced by the partner were 20 (9.3\%).

Conclusion: Findings of the study shows that the knowledge and awareness of contraceptive is high among health care providers however the practice of contraceptive method was comparatively high by their husbands. There is need to motivate the health care providers for contraceptive use in order to increase the prevalence in general population.
\end{abstract}

Keywords: Health Care Providers, Contraceptives, Knowledge, Practice, Attitude

\section{Introduction}

Pakistan's estimated population in 2014 is over 199 million, making it the world's sixthmost-populous country, behind Brazil and ahead of Nigeria. The Total Fertility Rate (TFR) of Pakistan is 2.86 children born/woman in (2014). According to UN projections, cited by Mustafa (2015) "Pakistan will become the fourth most populous country by the year 2050". The growth rate of a country also depends upon the use of contraceptives. The contraceptive measures refer to the practices and methods of avoiding pregnancy or placing the interval between the births of children. The contraceptive prevalence Rate (CPR) is the percentage of women who are practicing, or whose life partners are practicing, any form of contraception. It is being considered that a healthy reproductive life is a right of couple, especially the women.

Reproductive rights were defined as "the basic right of all couples and individuals to decide freely and responsibly the number, spacing and timing of their children and to have the information and means to do so, and the right to attain the highest standard of sexual and reproductive rights"(Tavrow, 2010) The International Conference on Population and Development (ICPD), held in Cairo in 1994, cited by Tavrow, (2010) was noteworthy for achieving a global consensus that all people - regardless of age, parity, marital status, ethnicity, or sexual orientation - are entitled to reproductive health and rights. In clinics and hospitals, health care providers hold the information and means that can make people to realize these rights. In fact, health care providers with adequate knowledge, skills, attitude and practices can influence the people to enhance reproductive health and rights. 
South American Journal of Public Health

Volume 4, Issue 2, 2016

The eight millennium development goals (MDGs) were been identified as a target to achieve. Basically the target of the MDGs is to uplift the status of health of the public. Women's health relates to the number of birth and interval in between the birth. Interval in between the birth or birth spacing could be possible by the use of contraceptive measure by the couple. Contraceptive prevalence rate in Pakistan indicates the low rate of contraceptive practices which are $29.6 \%$.(WHO, 2010). Contraceptive prevalence rate is also one of the indicators of MDGs 5 which is related to the women health. In Pakistan, we are far away in achieving the MDGs. Dawson, (2015) stated that one way to reduce pregnancy/childbirth related deaths and illnesses is to reduce the number of unwanted pregnancies through the use of effective contraception. He further added that we know from the Pakistan Demographic \& Health Survey (PDHS) that more than a quarter of all pregnancies are unwanted. Preventing those pregnancies through contraceptive use (assuming 100\% effectiveness) could have averted 8,500 maternal deaths and 106,250 maternal morbidities.

As prevalence of contraceptive measure is low among the general population of Pakistan, it is important to know the contraceptive practice among the health care providers. According to Mustafa (2015) the role of health care provider that are female doctors, nurses, private practitioners, community-based distributors, midwives and nurse auxiliaries, pharmacists, and the assistants to all these are very important in imparting information related to contraceptive measure in reproductive health. "Providers have been characterized as service-delivery 'gatekeepers' or 'street-level bureaucrats', because generally they alone decide who will be permitted to obtain information or medical attention, and under what conditions”.

Health care providers play an important role in imparting health education to the public. In order to provide the awareness among public we need to be aware of the health care provider's knowledge, attitude and practices. It is important to know whether the health care providers who are the health guider to women, they themselves are practicing the same or not. This study is design to assess the knowledge, attitude and practices of contraceptive measure among married health care providers working in the public hospitals situated in Lahore. The study will assess the knowledge, attitude and practices of contraceptive use, preferred method and find out the problems to practices. Moreover, this study will help identifying the value and belief of health care providers in practicing contraceptive methods.

\section{Definition of terms}

Health care provider: A person who is trained to care for sick or injured people and who usually works in a hospital and in a clinic (Dictionary, 2014).

Health care providers are the persons who hold diplomat or baccalaureate education in medical and nursing and provide services at all level of health care system.

Contraception: The deliberate use of artificial methods or other techniques to prevent pregnancy as a consequence of sexual intercourse. The major forms of artificial contraception are: barrier methods, of which the commonest is the condom or sheath; the contraceptive pill, which contains synthetic sex hormones which prevent ovulation in the female; intrauterine devices, such as the coil, which prevent the fertilized ovum from implanting in the uterus; and male or female sterilization.

Knowledge: Facts, information, and skills acquired through experience or education; the theoretical or practical understanding of a subject (Dictionaries, 2014).

Awareness or familiarity gained by experience of a fact or situation.

Practice: the actual application or use of an idea, belief, or method, as opposed to theories relating to it(Dictionaries, 2014).

Attitude: a settled way of thinking or feeling about something.

\section{Purpose}

1. To assess knowledge of contraceptive among health care providers.

2. To study the attitude towards contraceptives.

3. To study current practices about contraceptives. 
4. To identify the reasons of not practicing the same.

\section{Nature of study}

It is a descriptive study. The study mainly focused on the knowledge, attitude and practice of contraceptive methods among the health care providers of Lahore.

\section{Aim of the study}

The aim of this study is to endorse the contraceptive practices among women through health care providers

\section{Significance of the study}

The problem of low contraceptive use is an important contributing factor in fertility regulation and hence reduction of mortality and morbidity related to reproduction. Despite the fact that knowledge affects contraceptive use and reproductive health is related to the use of contraceptive measures. In literature, no study has been done in Pakistan to look at the factors associated with contraceptive knowledge, attitude and practices of health care providers.

The aim of this study is to assess the knowledge, attitude and practices of contraceptive method among health care providers of public hospitals in Lahore that most probably could be the contributing factor to the low contraceptive practices in Pakistan.

The results will help us understanding the knowledge, attitude and practices of contraceptive use and constraint in practices. The gained experience could be utilized to evaluate the need and identify the ways to motivate the women to practice the same. In addition, the study result will help to convince the higher authorities to implement such services to impart the knowledge of contraceptive use among public through health care provider at different health setting level. Therefore the number of unintended pregnancies can be reduced and family planning and reproductive health goals are met.

\section{Literature review}

Knowledge about contraceptives is very significant in order to use the appropriate method of spacing between children. Health care providers are the key persons who can provide awareness and can guide for better choices among contraceptive to the general population (Mbando, et al., 2011). It is important to know the preferred method of practices of contraceptives among health care providers because they are the health educators. In most of the studies it was found that education is the prime influencing factor. It may have a direct influence on fertility, since education affects the attitudinal and behavioral patterns of the individuals. A number of Knowledge Attitude and Practice survey have been carried out covering different population groups (Thapa, et al., 2015\& Rao, et al., 2005). A survey conducted in Manipur concluded that the use of modern family planning methods increases with education, while female sterilization prevalence decline sharply with women's education level (Ayub, et al., 2015). Moreover, recent analysis of Demographic Health Survey (DHS) for 25 developing countries confirms previous findings from the World Fertility Survey (WFS) that the better educated women are more likely to practice contraception (Lamidi, 2015). A study conducted by Samba (2014) on the Nurses and Nursing students about Emergency Contraceptives (EC) in Kenya mentioned that the level of knowledge of EC is poor and more information is needed.

A study conducted in Lahore at Aitcison Hospital reveals that the level of education of the women was 43 percent is matric however, 60 percent have the awareness related to contraceptives. In addition 54 percent women approved the use of contraception.

Another study conducted at Lahore, Pakistan revealed the low level of education that is 70 percent illiterate followed by the low prevalence of contraception that is 27.9 percent (Manzoor, et al., 2013).

The above studies clearly show the difference of urban and rural practices of contraception and the relationship of education too. 
South American Journal of Public Health

Volume 4, Issue 2, 2016

A study conducted with the women having unplanned pregnancy in Nigeria revealed the knowledge of contraception up to 85 percent among Nigerian women. The source of knowledge was the health care provider followed by mass media 38.4 percent and 21.4 percent respectively. The women agreed to the usefulness of contraception that is 86 percent however, only 8.7 percent women ever used the contraception. The constraints identified in this study were partner 54 percent, ill health 35 percent and religion contributed to 28 percent (Ross, et al., 2013).

Health Care Providers also have a major influence on the public's sexual and reproductive health because many people consider them to be the best source of information on these issues. Not only are providers thought to be more knowledgeable by virtue of their training, but they are also believed to be more likely to keep matters confidential. For low-literate people, or those with limited access to the media or the Internet, health providers may be their only source of scientific information (Tavrow, 2010).

The role of health care provider is very much significant in practicing contraceptives and reproductive health. Some important questions about the role of provider attitudes and practices still have not been adequately researched. To date, reviewers have found no empirical evidence concerning the impact of provider behaviors on clients (Tavrow, 2010).

Age is also an important determinant for contraceptive choice. CPR is most common in young adults' females as compare to the older adults. It is been concluded that majority (52.4\%) of the women using contraception were in the age group of 15-34 years. The choice of contraceptive method can be influenced by the partner choice, self- health, family choice, religion and number of children (Manzoor, 2013).

The present study aimed to assess the knowledge, attitude and practice of contraceptive methods to enhance the contraceptive practice in future. The contraceptive prevalence rate (CPR) is defined as the percentage of married women, aged 15-49 years, using modern and traditional methods of contraception (Mustafa, et al., 2015). Contraceptive prevalence rate of Pakistan is $29.6 \%$ as compare to India $56.3 \%$, Iran $73.7 \%$ that is high. But Afghanistan has $18.6 \%$ that is low in comparison to Pakistan (Rao, 2005). It shows that the prevalence rate of Pakistan is comparatively less than the neighboring countries except Afghanistan. There is an immense need to know the awareness, practice and attitude of the nurses because they play a key role in health industry. The preferences of health care providers and family planning educators directly influence the information provided to clients, thus swaying women's decisions concerning method adoption. Specific method recommendations by health care workers reflect their training and may be partially motivated by incentives to adopt the same preferences expressed by other individuals and institutions (Ross, et al., 2013).

There are many contraceptives available in the market but the choice of the contraceptive depends upon the efficacy of the drug and also the side effects. The first edition of the WHO's Medical Eligibility Criteria (MEC) states that, "WHO is giving priority to improving access to high quality care in family planning through a variety of strategies" and lists one of these strategies as "promoting the widest availability of different contraceptive methods so that people may select what is most appropriate to their needs and circumstances” (Harper, et al., 2012).

Approval of family planning was shown by $41 \%$ of males, as perceived by their wives in contrast to other studies of Sindh and Punjab, where $78 \%$ and $74 \%$ of husbands approved the use of contraceptive methods at the time of survey. Whereas, According to Pakistan Reproductive Health and Family Planning Survey 2000-2001 and Eastern Turkey, husband's disapproval was the main factor for not using any family planning method among married women (Mustafa, et al., 2015). Attitude of husband was found to be an important factor for contraception use (Zakar, et al., 2012 \& Alemayehu, et al., 2012).

Religion could be another predictor for contraceptive use. a study conducted in America states that the patterns of contraceptive use do not differ by religious affiliation among married women (Corbin, 2013). However the study conducted in Bangladesh where majority of the nurses are Muslims. Kamal, (2015) stated that The Quran does not prohibit birth 
control, nor does it forbid a husband or wife to space pregnancies or limit their number. Thus, the great majority of Islamic jurists believe that family planning is permissible in Islam.

Culture is another important predictor to influence the practices in the locality. Contraceptive use is likely to be affected by the fundamental cultural and social traits of a society (Yadav, et al., 2015).

\section{Methods}

\section{Setting}

This study was conducted in the capital of province of Punjab, Lahore. The target population was the health care providers of public hospitals located in Lahore. The setting includes the participant of Services Hospital, Lahore General Hospital, Sir Ganga Ram Hospital, Children Hospital, Myo Hospital and Nawaz Sharif Social Security Hospital. The total population of married health care providers, having two or more children and working at public hospital was approximately up to 600 . The subjects were selected on the basis of convenient sampling technique. The health care providers who were having two or more children and willing to response the questionnaire included in the study. Questionnaire were distributed in all six setting through a group of helper and received back after completing the questions.

\section{Study design}

A cross sectional descriptive study design was adopted.

\section{Population}

The study population was all married health care providers working at the public hospitals in Lahore. The population also includes the health care providers who have number of children two or more. Population was based on different Hospitals located in territory of Lahore.

\section{Inclusion criteria}

The inclusion criterion of study was all married health care providers who have two or more children and working in the different public hospital in Lahore

\section{Exclusion criteria}

All married health care providers who have one or no child and also not working in public hospital were excluded in the study and those who do not want to take the part in the study

\section{Sampling}

Sampling technique is a way of selecting the participant from the target population and selecting the subject to be the part of the research. The study sample was followed by the set inclusive criterion based on none randomized convenient sampling technique. The subjects were free to participate in the study.

\section{Sampling technique}

Sampling technique is a way of selecting the participant from the target population and selecting the subject to be the part of the research. The study sample was followed by the set inclusive criterion based on none randomized convenient sampling technique. The subjects were free to participate in the study.

\section{Research instrument}

A well-constructed close ended and choice selection questionnaire was developed by consulting the literature and discussion with the supervisor. The questionnaire was distributed to ten persons to check the understanding of the questions. 
South American Journal of Public Health

Volume 4, Issue 2, 2016

\section{Data gathering procedure}

The pilot testing of the questionnaire was done on ten persons to assess the understanding of the questions. Later on, the questionnaires were distributed in six setting of public hospitals that include Lahore General Hospital, Children Hospital, Services Hospital, Sir Ganga Ram Hospital, Myo Hospital and Nawaz Sharif Social Security Hospital. The questionnaire were distributed among the health care providers who meet the inclusion criteria after developing the complete understanding of questionnaire to them and collected back after the response was filled by the respondent.

\section{Methods used to analyze data}

The data was entered by the primary researcher on Statistical Package for Social Sciences (SPSS) (version 21) computer program on personal laptop. Percentages, mean of different variables are calculated by using the descriptive statistics. Tables and graphs are been developed to portrayed the data, also to explain and discuss the variables.

\section{Study timeline}

The study was done from Feb 2015 to January 2016.

\section{Ethical consideration}

Confidentiality was assured by not writing the name and personal information and willingness was obtained prior responding to the questionnaire. All information in this study is been kept confidential except to disseminate at required places.

\section{Results}

Table 1: Socio demographic characteristics of the participants $(n=216)$

\begin{tabular}{|l|l|l|}
\hline \multicolumn{1}{|c|}{ No of Children } & $(\mathbf{n}=\mathbf{2 1 6})$ & \multicolumn{1}{c|}{ Percent } \\
\hline 2 & 94 & 43.5 \\
\hline 3 & 74 & 34.3 \\
\hline 4 & 26 & 12.0 \\
\hline 5 & 14 & 6.5 \\
\hline$>5$ & 8 & 3.7 \\
\hline Total & 216 & 100.0 \\
\hline Characteristics & $(\mathbf{n}=\mathbf{2 1 6})$ & Percentage \\
\hline Age in Years & $(\mathbf{n}=\mathbf{2 1 6})$ & Percent \\
\hline$>20-30$ Years & 32 & 14.8 \\
\hline $31-40$ years & 108 & 50.0 \\
\hline 41 and above & 76 & 35.2 \\
\hline Total & 216 & 100.0 \\
\hline Income per Month & $\mathbf{( n = 2 1 6 )}$ & Percent \\
\hline $10,000-20,000$ & 76 & 35.2 \\
\hline $20,001-30,000$ & 58 & 26.9 \\
\hline $30,001-40,000$ & 50 & 23.1 \\
\hline$>40,000$ & 30 & 13.9 \\
\hline No Response & 2 & .9 \\
\hline Total & 216 & 100.0 \\
\hline Academic Qualification & $(\mathbf{n}=\mathbf{2 1 6}$ & Percent \\
\hline MA/MSC & 10 & 4.6 \\
\hline BA/BSC & 68 & 31.5 \\
\hline FA/FSC & 40 & 18.5 \\
\hline Matric & 86 & 39.8 \\
\hline No Response & 12 & 5.6 \\
\hline & & \\
\hline
\end{tabular}




\begin{tabular}{|l|l|l|}
\hline Total & 216 & 100.0 \\
\hline Professional Qualification & $(\mathbf{n = 2 1 6 )}$ & Percent \\
\hline Nurse Midwife & 190 & 88.0 \\
\hline BSN & 22 & 10.2 \\
\hline NSN & 2 & .9 \\
\hline PhD Nursing & 2 & .9 \\
\hline Total & 216 & 100.0 \\
\hline
\end{tabular}

Table 2- Knowledge and awareness regarding contraception

\begin{tabular}{|l|l|l|}
\hline Knowledge about Contraceptive & $(\mathbf{n = 2 1 6})$ & Percentage \\
\hline Yes & 212 & 98.1 \\
\hline No & 4 & 1.9 \\
\hline Total & 216 & 100.0 \\
\hline Self -Study & 18 & 8.3 \\
\hline Professional Study & 172 & 79.6 \\
\hline Family Conversation & 10 & 4.6 \\
\hline Community Discussion & 10 & 4.6 \\
\hline No Response & 6 & 2.8 \\
\hline Total & 216 & 100.0 \\
\hline Material Availability & $\mathbf{( n = 2 1 6 )}$ & Percentage \\
\hline Yes & 204 & 94.4 \\
\hline No & 4 & 1.9 \\
\hline No Response & 8 & 3.7 \\
\hline Total & 216 & 100.0 \\
\hline Contraceptive Resource Place & $\mathbf{( n = 2 1 6 )}$ & Percentage \\
\hline Family Planning Clinic & 50 & 23.1 \\
\hline Health Centre & 18 & 8.3 \\
\hline Hospital & 82 & 38.0 \\
\hline Drug Store & 46 & 21.3 \\
\hline General Store & 6 & 2.8 \\
\hline No Response & 14 & 6.5 \\
\hline Total & 216 & 100.0 \\
\hline
\end{tabular}

Table 3- Practices of contraception

\begin{tabular}{|l|l|l|}
\hline Contraception methods for users & $(\mathbf{n}=\mathbf{2 1 6})$ & Percentage \\
\hline Withdrawal Method & 20 & 9.3 \\
\hline Condom & 74 & 34.3 \\
\hline Norplant Capsule & 4 & 1.9 \\
\hline Intra Uterine Devices & 28 & 13.0 \\
\hline Contraceptive Pills & 34 & 15.7 \\
\hline Contraceptive Injections & 16 & 7.4 \\
\hline Calender / Rhythem Methods & 4 & 1.9 \\
\hline Multiple Option & 2 & .9 \\
\hline Not Using & 34 & 15.7 \\
\hline Total & 216 & 100.0 \\
\hline Constrain to Use Contraceptives & $(\mathbf{n}=\mathbf{2 1 6})$ & Percentage \\
\hline Yes & 74 & 34.3 \\
\hline No & 134 & 62.0 \\
\hline No Response & 6 & 2.8 \\
\hline Total & 214 & 99.1 \\
\hline Missing & 2 & .9 \\
\hline
\end{tabular}


South American Journal of Public Health

Volume 4, Issue 2, 2016

\begin{tabular}{|l|l|l|}
\hline Types of Constrain & $(\mathbf{n = 2 1 6})$ & Percentage \\
\hline Religious & 12 & 5.6 \\
\hline Cultural & 6 & 2.8 \\
\hline Family & 18 & 8.3 \\
\hline Partner & 20 & 9.3 \\
\hline Self -Health & 18 & 8.3 \\
\hline No Response & 6 & 2.8 \\
\hline Total & 80 & 37.0 \\
\hline No Constrain & 136 & \\
\hline Total & 216 & \\
\hline
\end{tabular}

Table 4: Attitude towards contraception

\begin{tabular}{|l|l|l|}
\hline Contraceptive Usage Regularity & $(\boldsymbol{n}=\mathbf{2 1 6})$ & Percentage \\
\hline Yes & 148 & 68.5 \\
\hline No & 62 & 28.7 \\
\hline No Response & 6 & 2.8 \\
\hline Total & 216 & 100.0 \\
\hline Attitude Towards Contraceptives & $\mathbf{( n = 2 1 6 )}$ & Percentage \\
\hline Yes & 148 & 68.5 \\
\hline No & 68 & 31.5 \\
\hline Total & 216 & 100.0 \\
\hline
\end{tabular}

\section{Description of the result}

In reference to the Table I, Majority of the participants (50 \%) was lies in the age of 31-40 years of age and $35.2 \%$ were above 41 years old. Related to the financial strength $35.2 \%$ of the participant had Rs:10,000-20,000 income per month. $26.9 \%$ and $23.1 \%$ had 20,00130,000 and $30,001-40,000$ respectively. $13.9 \%$ of the participant earns more than Rs: 40,000 per month. The academic qualification of the participant shows that the majority of the participants has secondary school certificate as the percentage shows $39.8 \%$ followed by 31.5 $\%$ nurses were undergraduates. Professional qualification revealed the data as $88 \%$ participants were Nurse Midwives and only $10.2 \%$ were BSN. Most of the participant $43.5 \%$ has 2 children followed by $34.3 \%$ of participant bears 3 children. Only 3.7\% of nurses carry more than five children. Results shows that $98.1 \%$ participants have knowledge about contraceptives and only $1.9 \%$ participants said that they have no knowledge about contraceptives.

Table No 2 shows that $79.6 \%$ got the knowledge from their Professional study and only $8.3 \%$ learnt by self-study. Related to the availability of contraceptive material $94.4 \%$ health care providers said that they have an easy access to contraceptive material. Moreover, out of 216, 50(23.1\%) nurses mentioned that Family Planning clinic and 82(38\%) said hospital is the resource place for contraceptives. In response to the question, regarding practices of contraceptives 74 (34.3\%) out of 216 prefer the use of condom by their husbands but 34 (15.7\%) used contraceptive pills. Intrauterine devices were the least preferred method among health care providers and 34 (15.7\%) health care providers were not using any method. The response to the question related to constrain in practicing contraceptives 134 (62\%) said that they do not have constrains in practicing contraceptives however, 74/216 (34.3\%) participants reported the constraints in using contraceptives. 20 out of 74 participants mentioned that they have constrains from their partner.

Table III shows the type of constraints. It reveals that self- health of the women hold them to practice contraceptives followed by the influence of religious practices that is 8.3 and 5.6 respectively. Result shows the attitude of the health care providers regarding regular use of contraceptives. 148 (68\%) out of 216 said that they use contraceptives regularly and 62 (28.7\%) were not using it regularly. In response to the question whether to use the 
contraceptives or not 180/216 (83.3\%) participant supported the idea of contraceptives. Only 16.7 percent of the participant remained against the idea of contraceptive usage.

\section{Discussion}

Family planning is defined by WHO as, "a way of thinking and living that is adopted voluntarily, upon the basis of knowledge, attitudes and responsible decisions by individuals and couples, in order to promote the health and welfare of family groups and thus contribute effectively to the social development of a country"

Pakistan is being $6^{\text {th }}$ most populous country in the world. It has 177 million populations with total fertility rate of 3.5 per woman and population growth rate 2.05 percent according to Economic Survey of Pakistan 2010-11. The growth rate of the Pakistan has begun to decline. But still it is very important to overcome the growth rate of the population for better utilization of economic resources. Family Planning is one of the most important measures to control the growth rate. Pakistan Government has started family Planning programs but not yet successful as in other countries.

The present study aimed to assess the knowledge, attitude and practice of contraceptive methods to enhance the contraceptive practice among health care providers in future. Results showed $98.1 \%$ have knowledge about contraceptives as compared to $97.4 \%$ and $99 \%$ in studies conducted at Lahore (Zakar, et al., 2012). The knowledge of the participant is high as they all are health care providers. The source of knowledge of $79.6 \%$ participants was their professional qualification followed by self- study $8.3 \%$. Community and family discussions remained at $4.6 \%$ as the source of their knowledge; however $2.8 \%$ did not response. In India, social circle (70\%) and media (39\%) were the main sources of awareness (Relwani, et al., 2012)

Related to the availability of contraceptive material $94.4 \%$ participant said that the contraceptives are easily available to them as compare to number of studies that shown a close correlation between the travel times from a woman's home to any health clinic and the likelihood that she will use a contraceptive. In Bangladesh, couples were two and a half times less likely to practice contraception if acquiring a method required traveling for 30minutes or more to a clinic (Arora, et al., 2013). In this study the participants are health care providers and contraceptives/ family clinics are available in mostly hospitals so they can have an easy access to the material. Moreover, 38\% participants responded that they got the material from hospital as compare to the results of Campbell that her study showed most of the participant knew that contraceptive were available in Government Hospital (62.8\%) and Medical shops (52.5\%)(Sathar, 2013).

This study revealed that $84.3 \%$ interviewed participants were using contraceptives as compare to the contraceptive prevalence rate (CPR), or the percentage of married, non-pregnant women using both modern and traditional methods of contraception, rose from 12 percent in 2000-01 to 28 percent in 2010-11, but has remained around 30 percent since then (Ayub, 2015). That shows the high prevalence rate in health care providers.

The preferred methods of contraceptives by users were condom (34.3\%) by their partners and $(15.7 \%)$ were using oral contraceptive pills as compare to the study done by NajafiSharjabad (2013) The most common method chosen was the barrier method (15\%), followed by IUCD (10\%) and the pill (10\%) in Pakistan. In another study conducted by Anjum (2014) the Oral contraceptive pills were the predominant method used (32\%). Health care providers that were not using contraceptives were $15.7 \%$ as compare to non-users proportions were 91.5\% (Bulto, et al., 2014). Two more studies showed 55\% and $44.6 \%$ of non-users (Desai, 2013 \& Tilahun, 2013). The prevalence rate of contraceptive among health care providers of Lahore is significantly higher in this study as compare to shared figures.

In the response of questions asked regarding constrains 50.5 percent of the total participant did not response. Out of 45.5 percent (34.6\%) respondents accepted to bear the constrain in practicing the contraceptive and $62.6 \%$ said they do not have any constrains of using contraceptives. The type of most common constrain (9.3\%) from partner. As Avidime (2013) 
South American Journal of Public Health

Volume 4, Issue 2, 2016

mentioned in his study that cultural and social constraints such as husband's approval prevented this demand from being converted into family planning use. Moreover, (8.3\%) constrains were due to self -health and family influence. The study conducted in Lahore support this study as $8.33 \%$ constraint was reported by the women is family.

Majority of the couples were not in favor of regular use of contraceptive drugs. The relationship between fertility intention and childbearing - and the link between fertility intention and contraceptive use-are strongly affected by other, independent attitudes, such as the attitude toward contraception itself (Yoo, et al., 2014). The present study depicts the positive attitude of health care providers toward contraceptive use as shown in figure13. In response to the question whether to use the contraceptive or not, 83 . 3\% of nurses showed positive attitude while $16.7 \%$ of participant did not support the idea. This study differ the results of Manzoor (2013) who found the positive attitude of participant $54 \%$ and disapproval $32 \%$. This study signifies the knowledge, attitude and practices of contraceptive among health care providers as compare to the present contraceptive rate of Pakistan 30\%.

\section{Limitations}

This study has several limitations as the sample size was small and the study done only on female health care providers and their partners were not with them during interview. The responses of male partners were not taken. Moreover, study focused only female health care providers working in government hospitals of Lahore that is urban area. The nurses of private hospital and rural health care facilities were not the part of this study. Further studies can be replicate on the health care providers working in the private hospitals as well as health workers of peripheral health care facilities. In addition, health care providers include other team members too but this study had not included them.

\section{Conclusion}

Findings of this study shows that majority of the health care providers have knowledge about contraceptives and its use. Reproductive health and family planning methods are been taught in the curriculum of the nurses and doctors so the professional qualification is the main source of awareness. Material is available to majority of the participants from health clinics and hospital.

The most common method in use was condom by their partners but contraceptive pills and intrauterine devices were the choice of participants. All participants were not using the contraceptive methods. Moreover, mostly participants have no constrains in using contraceptives. However, the participants who were facing constrains in use of contraceptives was due to partner, family and self- health. In addition, mostly participants used contraceptives regularly and showed positive attitude towards its use.

Increasing knowledge, awareness and importance of contraceptives among health professionals is important in order to increase awareness and contraceptive prevalence among general population of reproductive age.

\section{Recommendations}

So far, this study has depicted the sufficient knowledge and practice of contraceptives among health care providers, however, their attitude towards encouragement to general population is not evaluated. There is need to evaluate the role of health care providers in promoting contraceptive use among general population. The promotion of advance methods of contraceptives should be there so the clients can make choices among the methods.

There should be awareness programs regarding the use, effects and side effects of contraceptives. A policy should be introduced for an easy access of family planning centers and contraceptive drugs. The government should make sure the availability of the contraceptive drugs at peripheral level. There is an immense need of awareness programs for couples to overcome the barriers from male partners. 
Further studies should be planned to evaluate the knowledge, attitude and practice of lady health visitors, lady health worker and midwives as these health care provider mostly work at rural and peripheries of the country and influence the public.

\section{References}

[1.] Alemayehu, M., Belachew, T., \& Tilahun, T. (2012). Factors associated with utilization of long acting and permanent contraceptive methods among married women of reproductive age in Mekelle town, Tigray region, north Ethiopia. BMC pregnancy and childbirth, 12(1), 1.

[2.] Anjum, S., Durgawale, P. M., \& Shinde, M. (2014). Epidemiological Correlates of Use of Contraceptives Methods and Appraisal of Health Education on Status of Knowledge and Practices among Married Woman. International Journal of Science and Research (IJSR), 3(2), 203-210.

[3.] Arora, P., Bajpai, R. C., \& Srivastava, R. (2013). Emergency contraception: a study to assess knowledge, attitude and practices among female college students in Delhi. Hospital, 12(6.0), 2-7.

[4.] Avidime, S., Aku-Akai, L., Mohammed, A. Z., Adaji, S., Shittu, O., \& Ejembi, C. (2014). Fertility intentions, contraceptive awareness and contraceptive use among women in three communities in Northern Nigeria. African Journal of Reproductive Health, 14(3), 65-70.

[5.] Ayub, A., Kibria, Z., \& Khan, F. (2015). Assessment of Knowledge, Attitude and Contraceptive use in Married Women of Peshawar. Journal of Dow University of Health Sciences, 9(1).

[6.] Bulto, G. A., Zewdie, T. A., \& Beyen, T. K. (2014). Demand for long acting and permanent contraceptive methods and associated factors among married women of reproductive age group in DebreMarkos Town, North West Ethiopia. BMC women's health, 14(1), 1.

[7.] Corbin, C. M. (2013). The contraception mandate. Northwestern University Law Review, 107, 1469.

[8.] Dawson, A., Tran, N. T., Westley, E., Mangiaterra, V., \& Festin, M. (2015). Workforce interventions to improve access to emergency contraception pills: a systematic review of current evidence in low-and middle-income countries and recommendations for improving performance. BMC health services research, 15(1), 1.

[9.] Desai, R. M. (2013). Knowledge, attitude and practice of contraception among women attending a tertiary care hospital in India. Parity, 41(45), 04.

[10.] Dictionaries, O. (2014). Language matters. VERB (diets, dieting, dieted). URL http://www.oxforddictionaries.com/us/definition/american_english/diet (accessed November 5, 2014).

[11.] Dictionary, M. W. (2014). Available at: http://www.merriam-webster.com/dictionary/ambiguous (accessed September 24, 2010).

[12.] Harper, C. C., Henderson, J. T., Raine, T. R., Goodman, S., Darney, P. D., Thompson, K. M., \& Speidel, J. J. (2012). Evidence-based IUD practice: family physicians and obstetrician-gynecologists. Family medicine, 44(9), 637.

[13.] Kamal, S. M. (2015). Socioeconomic factors associated with contraceptive use and method choice in urban slums of Bangladesh. Asia-Pacific Journal of Public Health, 27(2), NP2661-NP2676.

[14.] Lamidi, E. O. (2015). State Variations in Women's Socioeconomic Status and Use of Modern Contraceptives in Nigeria. PloS one, 10(8), e0135172.

[15.] Manzoor, I., Navied, U., Iqtidar, A., Shah, M., Waqas, A., \& Naseem, M. O. (2013). Prevalence of contraceptive practices in married women of Nainsukh village near Lahore. Biomedica, $29,82$.

[16.] Mbando, A. H. (2011). Contraceptive method choice among women attending at amtullabhai family planning clinic in Dar es Salaam (Doctoral dissertation, Muhimbili University of Health and Allied Sciences).

[17.] Mustafa, G., Azmat, S. K., Hameed, W., Ali, S., Ishaque, M., Hussain, W., \& Munroe, E. (2015). Family Planning Knowledge, Attitudes, and Practices among Married Men and Women in Rural Areas of Pakistan: Findings from a Qualitative Need Assessment Study. International journal of reproductive medicine, 2015.

[18.] Najafi-Sharjabad, F., Yahya, S. Z. S., Rahman, H. A., Hanafiah, M., \& Manaf, R. A. (2013). Barriers of modern contraceptive practices among Asian women: a mini literature review. Global journal of health science, 5(5), 181. 
South American Journal of Public Health

Volume 4, Issue 2, 2016

[19.] Rao, A. K. (2005). Client Demand Approach (CDA) in the Revised Family Welfare Programame-A Feasibility Study. In Regional Health Forum WHO South-East Asia Region (Vol. 5, pp. 42-7).

[20.] Relwani, N., Saoji, A., Kasturwar, N. B., Nayse, J., Junaid, M., \& Dhatrak, P. (2012). Emergency Contraception: Exploring the knowledge, attitude and practices of engineering college girls in Nagpur district of central India. National Journal of Community Medicine, 3(1), 14-19.

[21.] Ross, J., \& Hardee, K. (2013). Access to contraceptive methods and prevalence of use. Journal of biosocial science, 45(06), 761-778.

[22.] Sathar, Z. A. (2013). Family planning: a missing priority in Pakistan's health sector?. The Lancet, 381(9884), 2140-2141.

[23.] Somba, M. J., Mbonile, M., Obure, J., \& Mahande, M. J. (2014). Sexual behaviour, contraceptive knowledge and use among female undergraduates' students of Muhimbili and Dar es Salaam Universities, Tanzania: a cross-sectional study. BMC women's health, 14(1), 1.

[24.] Tavrow, P. (2010). Promote or discourage: how providers can influence service use. Social determinants of sexual and reproductive health: informing future research and programme implementation. Geneva: World Health Organization, 15-36.

[25.] Thapa, S., Paudel, I. S., Bhattarai, S., Joshi, R., \& Thapa, K. (2015). Factors Affecting IUCD Discontinuation in Nepal A Nested Case-Control Study. Asia-Pacific Journal of Public Health, 27(2), NP1280-NP1287.

[26.] Tilahun, T., Coene, G., Luchters, S., Kassahun, W., Leye, E., Temmerman, M., \& Degomme, O. (2013). Family planning knowledge, attitude and practice among married couples in Jimma Zone, Ethiopia. PloS one, 8(4), e61335.

[27.] World Health Organization.(2010). World health statistics 2010. World Health Organization.

[28.] Yadav, D., \& Dhillon, P. (2015). Assessing the impact of family planning advice on unmet need and contraceptive use among currently married women in Uttar Pradesh, India. PloS one, 10(3), $\mathrm{e} 0118584$.

[29.] Yoo, S. H., Guzzo, K. B., \& Hayford, S. R. (2014). Understanding the complexity of ambivalence toward pregnancy: does it predict inconsistent use of contraception?. Biodemography and social biology, 60(1), 49-66.

[30.] Zakar, R., Zakar, M. Z., Mikolajczyk, R., \& Krämer, A. (2012). Intimate partner violence and its association with women's reproductive health in Pakistan. International journal of gynecology \& Obstetrics, 117(1), 10-14. 